\title{
A FALSE POSITIVE GALLIAZZI SIGN AND MIMICKS EXCESSIVE ANTEVERSION OF FEMUR: DUE TO CONTRACTURE OF GLUTEUS MEDIUS MUSCLE
}

\author{
Ramesh Chandra Vadapalli *.
}

Assistant professor, Department of Orthopaedics, Santhiram Medical College \& General Hospital, Nandyal, Kurnool, Andhra Pradesh, India.

\section{ABSTRACT}

Isolated gluteus medius contracture limiting external rotation of thigh gives rise to a false positive galliazzi sign and mimicks excessive anteversion of femur. The purposes of this study is to report clinical and experimental investigations of a vascular necrosis which follows closed reduction of congenital hip dislocation with particular reference to its pathogenesis, prognosis and prevention. 5 patients (males, 3; females, 2), of 5 to 12 years old Childs diagnosed with GMC and were treated in the orthopedic department of Birds hospital, Tirupathi, Chitoor, A.P., They were inability to sit crossed leg, able to squat only when their thigh was internally rotated and abducted. Clinical examination revealed a tight band of tissue in the hip region, running from the iliac crest to the greater trochanter, laterally were included in the study. We found from the present study internal rotation contracture of hip due to contracture of gluteus medius muscle, this is the false positive galleazzi sign may be due to the contracted muscle causing abduction of hip in flexion, pulling the pelvis down by same mechanism as maximus contracture does, a condition not previously reported in the literature so far, to the best of our knowledge. After the fibrous band was incised full external rotation was then possible and the galleazzi sign was negative.

KEY WORDS: Galleazzi Sign, Mimicks Excessive Anteversion Of Femur, Gluteus Medius Muscle, And Crossed Leg.

Address for correspondence: Dr. Ramesh Chandra Vadapalli, Assistant professor, Department of Orthopaedics, Santhiram Medical College \& General Hospital, Nandyal, Kurnool, Andhra Pradesh, India.E-Mail: drrameshvadapally@gmail.com

\begin{tabular}{|c|c|c|}
\hline \multicolumn{3}{|c|}{ Online Access and Article Informtaion } \\
\hline $\begin{array}{l}\text { Quick Response code } \\
\text { 口isy }\end{array}$ & \multicolumn{2}{|c|}{$\begin{array}{l}\text { International Journal of Integrative Medical Sciences } \\
\text { Wwww.imedsciences.com }\end{array}$} \\
\hline Dol: $10.16965 /$ ijims.2018.112 & $\begin{array}{l}\text { Received: 04-05-2018 } \\
\text { Reviewed: 04-05-2018 }\end{array}$ & $\begin{array}{l}\text { Accepted: 25-05-2018 } \\
\text { Published: 05-06-2018 }\end{array}$ \\
\hline Source of Funding: Self & \multicolumn{2}{|c|}{ Conflicts of interest: None } \\
\hline
\end{tabular}

\section{BACKGROUND}

Degeneration, necrosis, and fibrosis of the gluteal muscles and fascia, leading to serious limitation of hip movements are the clinical syndrome pathologically characters of Gluteal muscle contracture (GMC) [1].

It is congenital or iatrogenic, is not uncommon and exists worldwide, involving the US, France, Italy, Poland, Australia, Spain, China, and India [2-9]. Most of the reports concerned with contracture of quadriceps muscle, contracture of deltoid muscle, gluteus maximus, gluteus medius, and the triceps muscle, bilateral and multiple contractures.

It usually arises from repeated intramuscular injection into the gluteal region during childhood, more commonly in China [10].

GMC is diagnosed primarily by history and some important physical examinations, Symptoms and signs [11].

Symptoms: History of repeated intramuscular injections into the buttocks, Abduction and external rotation with limited flexion and adduction of affected hip, Unable to bring knees together during squatting, sits in frog-leg position, Out-toeing gait/cannot walk in straight line, 
Snapping sound while squatting, Unable to cross or overlap legs, Knee crepitus, and Anterior knee pain.

Signs: Ober's sign positive, Active flexion test positive, Reverse Ober's sign positive, Palpable snapping sound while squatting, Pelvic tilt toward severe side, Compensatory scoliosis, Apparent leg length discrepancy (affected leg looks longer), Flattened or cone-shaped buttock, and Dimpling of skin in the buttock area.

Imaging: Radiological findings, in some situations, could be helpful to support the diagnosis and rule out other pathological conditions. Plain radiograph: Iliac hyper-dense line sign along the lateral iliac cortex in anteroposterior (AP) view, Pelvic obliquity, Other signs: Increase in the neck shaft angle, Reduction in center-edge angle and External rotation of proximal femur

Magnetic resonance imaging (MRI) Primary features: Marked atrophy of gluteus maximus, Intramuscular fibrous band

Secondary features: Medial retraction of the distal belly and tendon, Posteromedial retraction of the iliotibial tract at attachment, depressed groove at the muscle-tendon junction, and External rotation of proximal femur.

Computed tomography (CT) scan: Atrophy of gluteal muscles, Calcification and necrosis of the injection site, Curly band of fascia, and Widened gluteal muscle clearance

Ultrasonography (USG): Thinning of involved muscles, Hyperechoic bands within the muscle bundles suggest fibrosis.

Classification systems of gluteal muscle contracture have been established by different authors in the past which mainly focused on the cosmetic aspect rather than the functional aspect of the disease [12-14]. Zhao et al, and Ye et al in proposed classifications of GMC that are fairly based on the clinical manifestations and anatomic changes and address the functional aspect of the disease $[15,16]$. Both the classification systems do not seem to be much different from each other and both the classification systems are practically more reliable in understanding the disease pathology and useful in choosing the correct treatment options [17]. Zhao also recommended treatment options according to the severity of the disease as a non-operative or arthroscopic treatment for level I disease, an operative treatment especially an arthroscopic treatment for level II disease, and an operative treatment under direct vision with a conventional incision for level III disease [15].

Severe gluteal muscle contracture may result in pelvic tilt and leg length discrepancy. Most commonly reported cases are those following intramuscular injection in the gluteal region although congenital contracture is an uncommon but important occurrence. This condition has most often been reported in children of school going age. These patients often present with difficulty in squatting, limitation of hip motion or specific deformities and surgery is the treatment of choice; conservative treatment only aggravates the condition. The purpose of this paper is to report a case of internal rotation contracture of hip due to contracture of gluteus medius muscle, a condition not previously reported in the literature so far, to the best of our knowledge.

\section{MATERIALS AND METHODS}

Fig. 1: Before treatment.

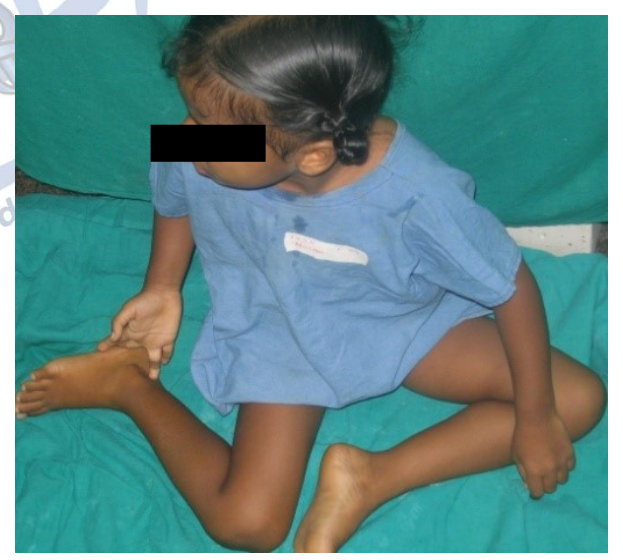

5 patients (males, 3 ; females, 2), of 5 to 12 years old Childs diagnosed with GMC and were treated in the orthopedic department of Birds hospital, Tirupathi, Chitoor, A.P., were followed for 6 months every patient, and written consent for publication was obtained from the patients or their relatives. They were inability to sit crossed leg, able to squat only when their thigh was internally rotated and abducted. They were not received any intramuscular injections in the gluteal region. They were no history of birth anoxia. Child's developmental milestones were within normal limits. They never had any trauma 
or an abscess in the gluteal region, able to walk normally and could bend forwards freely. Clinical examination revealed a tight band of tissue in the hip region, running from the iliac crest to the greater trochanter, laterally were included in the study.

Fig. 2: Operation at Gluteal region

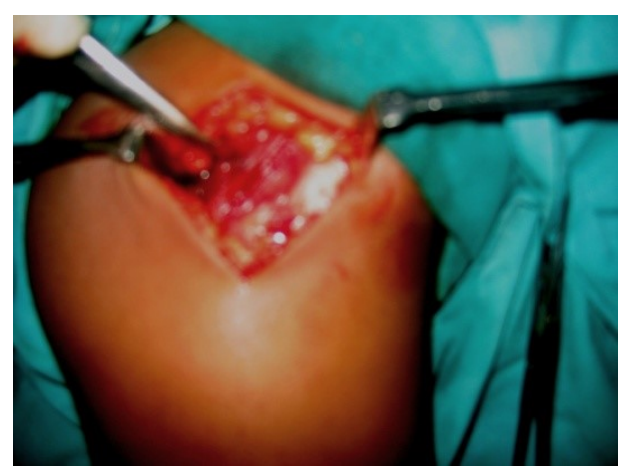

Fig. 3: Post Operation of Gluteus muscle.

\section{Management}

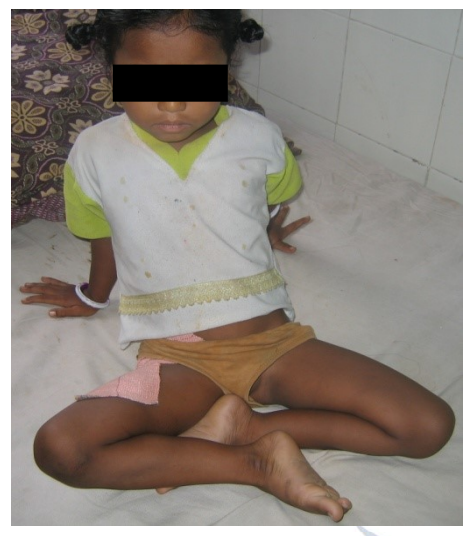

\section{Non-operative management (NOM)}

Massage and physiotherapy, such as shortwave diathermy and hot packs, were the basic NOM techniques for patients. Following NOM, the patients could engage in the following exercises: squats with the knees close to each other, walking on a line, and moving the hips with effort. Active and passive exercise methods should be undertaken.

\section{Operative Procedure}

Under general anaesthesia, with the hip in extension, an $8 \mathrm{~cm}$ straight incision was applied extending from the tip of the greater trochanter towards the iliac crest. The gluteus maximus and the tensor fascia muscles were found to be normal. The gluteus medius muscle was approached by splitting the gluteus maximus bluntly. The anterior half of the gluteus medius muscle was glistening and was felt as a thick fibrotic band of tissue. This fibrotic band extended till the greater trochanter. After incising the fibrotic band transversely, at the trochanter level, the hip could be freely externally rotated. Hip was mobilized from $3^{\text {rd }}$ post-operative day.

\section{RESULTS AND OBSERVATIONS}

There were 5 patients (males, 3; females, 2) and were between 5-12 age and diagnosed with GMC included in this study. There was no a visible scar or dimples on the skin in the hip region. There was no snapping in the hip. Hip joint movements showed flexion of 0 to 120 degrees, extension of 0 to 10 degrees, abduction of 0 to 40 degrees, and adduction was 0 to 10 degrees in extension of the hip. There was however, no adduction possible in flexion of the joint. Internal rotation in extension was 5 to 40 degrees and 10 to 45 degrees in flexion. External rotation was not possible in extension and in flexion of the hip. Anteversion of the femur with Craig's test was found to be normal for the age. There was no true limb length discrepancy. Galleazzi sign however, was false positive, showing an apparent lengthening on the right thigh. Radiographs of pelvis and femur were normal. No effective rate of NOM in all 5 children. Operative treatment was performed; all patients had excellence or fair results, while none failed. Hip was mobilized from $3^{\text {rd }}$ post-operative day. On the $5^{\text {th }}$ post-operative day Childs were able to sit crossed leg. At 6 month follow-up they were able to sit freely and had no complaints. External rotation was found to be 0 to 45 degrees. Complications after operative management only appeared patients, and included scar swelling present 1case, No hematomas, no infections, and wound dehiscence present 1 case.

\section{DISCUSSION}

Gluteus muscle contracture syndrome is a debilitating disorder, often causing marked reduction in the quality of life. This condition most often occurs in children aged 6-18 years and is more common in boys than in girls [18, 19]. A childhood incidence of $1-2.5 \%$ [20] and a morbidity of $1.36 \%$ in affected individuals have been reported [21]. Several possible etiological factors have been suggested as a cause of muscle fibrosis. Among these are, genetic causes, congenital causes and postnatal causes, 
mainly multiple injections, poliomyelitis, cerebral palsy, keliods, collagen vascular diseases, and compartment syndrome. Fibrosis due to intramuscular injections has been well described in the literature. Contracture of deltoid muscle, triceps muscles in the upper limb, and contracture of the quadriceps muscle, tensor fascialata muscle, gluteus maximus and gluteus medius muscles in the lower limb have been reported in the literature so far [15]. The authors implicate a congenital cause for the fibrosis; however, an injection fibrosis cannot be excluded fully. Contracture of the quadriceps muscle is by far the most commonly involved. Abduction contracture of the hip is also well described entity resulting mostly due to injection fibrosis. Abduction contracture at hip is caused by gluteus maximus, gluteus medius and tensor fascialata contracture. Patients with gluteus maximus contracture cannot squat with knees together and cannot adduct the hip in flexion. And can only squat by abducting the hip, mimicking frog leg position [11].

The patient cannot bend forward fully due to limitation of flexion. Sometimes a dimple on the skin or a groove in gluteal region and a fibrous band may be palpable. These bands can be detected with the help of MRI [22].

Gluteus maximus muscle is the chief hip extensor and a weak abductor of the hip, in sitting posture. The contracted gluteus maximus muscle pulls the iliotibial band backward, thus changing the axis of the muscle in relation to hip joint. The motion of hip in sagittal plane is limited anteriorly and thus adduction of hip in sitting position is limited. Contracture of gluteus medius is seen in poliomyelitis, cerebral palsy and injection fibrosis [23]. In cerebral palsy, gluteus medius, along with gracilis and medial hamstrings contributes to the characteristic internal rotation gait. Isolated contracture of gluteus medius muscle, causing predominantly internal rotation contracture has not been reported in the literature, so far. It results from fibrosis of the anterior most fibres gluteus medius, which are internal rotators of hip. Patient can't sit cross-legged as the amount of external rotation is limited [24].

They can sit with thigh internally rotated mimicking to have excessive anteversion. In present study the false positive galleazzi sign may be due to the contracted muscle causing abduction of hip in flexion, pulling the pelvis down by same mechanism as maximus contracture does. After the fibrous band was incised full external rotation was then possible and the galleazzi sign was negative. Intramuscular injections to the gluteal region are not advisable before two years of age as the bulk of these muscles are less and not fully developed.

\section{CONCLUSION}

In the present study the false positive galleazzi sign may be due to the contracted muscle causing abduction of hip in flexion, pulling the pelvis down by same mechanism as maximus contracture does. After the fibrous band was incised full external rotation was then possible and the galleazzi sign was negative. Intramuscular injections to the gluteal region are not advisable before two years of age as the bulk of these muscles are less and not fully developed.

\section{REFERENCES}

[1]. Valderrama JAF: A cause of limited flexion and adduction of the hip in children. J Bone Joint Surg. 1970;52:179.

[2]. Howard RC: latrogenic quadriceps and gluteal fibrosis. J Bone Joint Surg.1971;53:354.

[3]. Chigot PL, Vialas M: Fibroses rétractiles du moyen fessier. Rev Chir Orthop. 1969;55:154.

[4]. Motta A: La miosite fibrosa causa di limitazione articolare del ginocchion e dell'anca. Clin Ortop.1971;23:114-21.

[5]. Henvkovský O: Progressive fibrosis of the vastus intermedius muscle in children. A cause of limited knee flexion and elevation of the patella. J Bone Joint Surg. 1961;43:318-25.

[6]. Williams PF: Quadriceps contracture. J Bone Joint Surg.1968;50:278-84.

[7]. Fenollosa Gomez J, Quiles Galindo M: Retracción bilateral del gluteo mayor. Reo Ortop Traumat.1969;13:701-8.

[8]. Karlen A: Congenital fibrosis of the vastus intermedius muscle. J Bone Joint Surg. 1964;46:488-91.

[9]. Mehta MH: Bilateral congenital contracture of the ilio-tibial tract. J Bone Joint Surg. 1972;54:532-4.

[10]. Zha K, Liu G, Yang S, Cao F. Z-plasty for severe gluteal muscle contracture in children. J Orthop Surg (Hong Kong). 2016;24(3):383-6.

[11]. Rai S, Meng C, Wang X, Chaudhary N, Jin S, Yang S \& Wang $\mathrm{H}$. Gluteal muscle contracture: diagnosis and management options. SICOT J. 2017;3:1.

[12]. Brignall CG, Brown RM, Stainsby GD. Fibrosis of the gluteus maximus as a cause of snapping hip. A case report. J Bone Joint Surg Am. 1993;75(6):909-10. 
[13]. Shen YS. Abduction contracture of the hip in children. J Bone Joint Surg Br. 1975;57(4): 463-5.

[14]. Gonzalez R. Gluteal retractions: classification and treatment techniques. Aesthet Surg J. 2006;26(5):537-50.

[15]. Zhao CG, He XJ, Lu B, Li HP, Wang D, Zhu ZZ. Classification of gluteal muscle contracture in children and outcome of different treatments. BMC Musculoskelet Disord. 2009;10:34.

[16]. Ye B, Zhou P, Xia Y, Chen Y, Yu J, Xu S. New minimally invasive option for the treatment of gluteal muscle contracture. Orthopedics. 2012;35(12):e1692e1698.

[17]. Al Bayati MA, Kraidy BK. Gluteal muscle fibrosis with abduction contracture of the hip. Int Orthop. 2015;40(3):447-51.

[18]. Hang YS. Contracture of the hip secondary to fibrosis of the gluteus maximus muscle. J Bone Joint Surg Am. 1979;61(1):52-5.

[19]. Chung Dc, Ko YC, Pai HH. A study on the prevalence and risk factors of muscular fibrotic contracture in Jia-Dong Township, Pingtung County, Taiwan. Gaoxiong Yi Xue Ke Xue Za Zhi. 1989;5(2):91-5.

[20]. Liu Y, Wang Y, Xue J, Lui PP, Chan K. Arthroscopic gluteal muscle contracture release with radiofrequency energy. Clin Orthop Relat Res. 2009;467(3):799-804.
[21]. Sun X. An investigation on injectional gluteal muscle contracture in childhood in Mianyang City. Zhonghua Liu Xing Bing Xue Za Zhi. 1990; 11(5):2914.

[22].Vamshi Krishna Kotha, Rajasekhar Reddy, M. Venkateshwar Reddy, (Brig) Rangubatla Sathyanrayana Moorthy, Tatikonda Venkat Kishan. Congenital gluteus maximus contracture syndrome - a case report with review of imaging findings. J Radiol Case Rep. 2014; 8(4): 32-7.

[23]. Robert C. Grumet, Rachel M. Frank, Mark A. Slabaugh, Walter W. Virkus, Charles A. Bush-Joseph, MD, and Shane J. Nho. Lateral Hip Pain in an Athletic Population Differential Diagnosis and Treatment Options. Sports Health. 2010;2(3):191-6.

[24]. Klum E, Streicher H, Böhm H, Wagner P, Döderlein L. Causes and calculated predictors of Duchenne gait in adolescents and young adults with cerebral palsy. Z Orthop Unfall. 2015;153(1):85-92.

How to cite this article: Ramesh Chandra Vadapalli. A FALSE POSITIVE GALLIAZZI SIGN AND MIMICKS EXCESSIVE ANTEVERSION OF FEMUR: DUE TO CONTRACTURE OF GLUTEUS MEDIUS MUSCLE. Int J Intg Med Sci 2018;5(5):630-634. DOI: 10.16965/ijims.2018.112 